ferritin lower than $200 \mathrm{mcg} / \mathrm{L}$ and healthy blood donors. Haemachromatosis patients with a ferritin level above $200 \mathrm{mcg} / \mathrm{L}(\mathrm{n}=26)$ had significant increases in haemoglobin $(\mathrm{Hb})(\mathrm{P}<0.001)$, mean cell volume (MCV) $(\mathrm{P}<0.026)$, mean corpuscular haemoglobin $(\mathrm{MCH})$ $(\mathrm{P}<0.001)$ and mean corpuscular haemoglobin concentration (MCHC) $(\mathrm{P}<0.002)$.

Conclusion Patients with $\mathrm{C} 282 \mathrm{Y}$ homozygous haemachromatosis had a significantly higher $\mathrm{Hb}, \mathrm{MCV}, \mathrm{MCH}$ and $\mathrm{MCHC}$. There is a clear correlation between ferritin and these raised red cell indices. A ferritin greater than $200 \mathrm{mcg} / \mathrm{L}$ is associated with a significant increase these red cell indices. Further studies are required to determine whether this increase in red cell indices is reversible with therapeutic venesection.

Disclosure of Interest None Declared.

\section{PWE-137 FOUR PATIENTS WITH AMANITA PHALLOIDES POISONING}

doi:10.1136/gutjnl-2013-304907.425

1."S Vanooteghem, 'S Decock, 'J Arts, ${ }^{2} \mathrm{C}$ Verslype, 'P Van Hootegem. 'gastroenterology, Sint-Lucas General hospital Brugge, Brugge; '2hepatology, University Hospital Leuven, Leuven, Belgium

Introduction Mushroom poisoning is a rare problem. We report four concomitant cases of amatoxin intoxication, the most deadly cause of mushroom poisoning.

Methods Case

Four women, living together in a convent, were admitted because of nausea, vomiting and diarrhoea. Symptoms started approximately 10 hours after eating wild mushrooms, self-picked in the forest. Laboratory data, 24 hours after ingestion, showed normal liver enzymes in 2 patients and normal INR and bilirubin in all 4 patients. Because of suspected amatoxin intoxication, a therapy with intravenous fluid, $\mathrm{N}$-acetylcysteine and silibinin was started. 36 hours after intoxication, complaints of vomiting and diarrhoea improved in all 4 patients. Blood analysis however showed a dramatic increase of the liver enzymes in 3 of 4 patients (ALT-range 48 hours after ingestion: 558-1762 U/L), and an elevation of bilirubin and INR in all 4 patients. Two patients were transferred to a transplantcentre 48 hours after mushroom poisoning because they developed stage 2 hepatic encephalopathy. With maximal supportive therapy, all patients gradually improved from day 3 on. They were discharged from the hospital between 6 to 10 days after admission.

Results Discussion

Our patients showed the typical clinical syndrome of an amatoxin intoxication. This syndrome can be divided into 3 phases. The gastrointestinal phase (starts 6-40 hours after consumption) is characterised by vomiting and diarrhoea and lasts 12-24 hours. In amatoxin intoxication, symptoms develop typically more than 6 hours after ingestion, while other toxic mushrooms cause symptoms earlier, after $0.5-3$ hours. Blood analysis at this initial stage shows normal liver and kidney function. A careful history is very important, to avoid the risk that patients are discharged too early with a diagnosis of a common gastroenteritis. The second phase is characterised by an apparent recovery 36-48 hours after ingestion, while biochemistry shows a progressive increase of transaminases. In the third phase (2-6 days after ingestion), patients can develop hepatic failure, often complicated by renal failure. The therapy of amatoxin intoxication consists of supportive care and medical therapy with silibinin and $\mathrm{N}$-acetylcysteine. Therapy with activated charcoal can be beneficial, if started early after the intoxication. We did not treat our patients with activated charcoal because of vomiting and presentation of the patients 24 hours after ingestion. Patients who develop liver failure should be transferred to a transplantcentre.
Conclusion Amatoxin intoxication is a rare cause of liver failure. When suspected, careful monitoring of the liver function and treatment with silibinin and $\mathrm{N}$-acetylcysteine are mandatory.

Disclosure of Interest None Declared.

\section{PWE-138 TREATMENT OF PATIENTS WITH CHRONIC HEPATITIS C GENOTYPE 1 AND ADVANCED FIBROSIS WITH PROTEASE INHIBITORS- IL28B DISCORDANCE RESULTS IN EARLY VIRAL DECLINE BUT LATE RELAPSE}

doi:10.1136/gutjnl-2013-304907.426

1.*'S Tanwar, 'P M Trembling, 'B J Hogan, 'J Catt, 'S Glasgow, 'N Glover, 'M Ju, ${ }^{1} \mathrm{M}$ Hains, ${ }^{1} \mathrm{M} \mathrm{T}$ Moore, ${ }^{1} \mathrm{C}$ Velazquez, ${ }^{2} \mathrm{~T}$ Conibear, ${ }^{2} \mathrm{~W}$ Labbett, ${ }^{2} \mathrm{D}$ Irish, ${ }^{2} \mathrm{M}$ Macartney, ${ }^{2} \mathrm{~T}$ Haque, ${ }^{3} \mathrm{E}$ Nastouli, 'B Smith, ${ }^{1} \mathrm{P}$ Smith, ' $\mathrm{D}$ Suri, 'J A Oben, 'M G Jacobs, ' $\mathrm{G}$ M Dusheiko, 'W M Rosenberg. 'Institute for Liver and Digestive Health, Division of Medicine, University College London \& Royal Free London NHS Foundation Trust; ${ }^{2}$ Department of Virology, Royal Free London NHS Foundation Trust; ${ }^{3}$ Department of Clinical Microbiology and Virology, University College London Hospitals NHS Foundation Trust, London, UK

Introduction We report the impact of host and viral factors on treatment outcome in the first 53 patients who have completed therapy for CHC with either telaprevir or boceprevir, in combination with pegylated-interferon and ribavirin $(\mathrm{PEG} / \mathrm{R})$ at our centre. Methods Patients were treatment naïve or experienced with F3 or F4 fibrosis, CHC genotype1 and HCV RNA > 10,000 IU/ml. Data were collected on host and viral factors including single nucleotide polymorphisms (SNPs) in the IL28B gene noncoding region at sites rs12979860 and rs8099917.

Results 53 patients (42 Caucasian, 32 F4) were treated with TVR $(n=41)$ and BOC $(n=12)$. Seven patients were treatment naïve. Subtyping was unattainable in 2 patients. Thus far, 18 patients $(34 \%)$ have failed treatment and the remainder are being evaluated for SVR (24 patients with SVR-4 to date).

HCV viral negativity at triple therapy week 4 was associated with treatment success in patients with rs12979860CC and rs8099917TT and rs12979860non-CC and rs8099917non-TT (OR 20.2 P-value $<0.001$ ) but not in patients with discordance between the two IL28B polymorphisms (rs12979860non-CC and rs8099917TT, P-value $=$ NS). Despite $86 \%$ HCV RNA negativity at triple therapy week 4 , patients with discordant IL28B genotype results demonstrated a failure rate of $43 \%$ predominantly due to virologic breakthrough during PEG/R. In addition, all patients who ultimately failed therapy after attaining eRVR and qualifying for shortened therapy had IL28B genotype discordance. Multivariate logistic regression identified that HCV negativity at triple therapy week 4 ( $p$-value $<0.001$ ), rs12979860 (p-value $=0.02)$ and rs8099917 $(p$-value $=0.001)$ were all independent predictors of treatment outcome after accounting for the remaining factors as potential confounders.

\section{Abstract PWE-138 Table}

\begin{tabular}{lll}
\hline & $\begin{array}{l}\text { Undetectable HCV-RNA, } \\
\text { triple therapy wk-4 }\end{array}$ & $\begin{array}{l}\text { EOT HCV-RNA } \\
\text { negative }\end{array}$ \\
\hline rs12979860 CC, rs8099917TT $(\mathrm{n}=10)$ & $90 \%$ & $100 \%$ \\
rs12979860 non-CC, rs8099917TT $(\mathrm{n}=14)$ & $85 \%$ & $57 \%$ \\
rs12979860 non-CC, rs8099917non-TT & $69 \%$ & $66 \%$ \\
$(\mathrm{n}=29)$ & & \\
\hline
\end{tabular}

Conclusion In our prospective cohort of $\mathrm{CHC}$ patients with advanced fibrosis treated with PIs, HCV RNA negativity at triple therapy week 4 and both IL28B genotypes were independent predictors of treatment outcome. Despite similar rates of early viral suppression, our preliminary data indicate more favourable end of treatment results for rs12979860CC and rs8099917TT versus rs12979860non-CC and rs8099917TT.

Disclosure of Interest None Declared. 